\title{
Failure of colonoscopic surveillance in ulcerative colitis
}

\author{
D A F Lynch, A J Lobo, G M Sobala, M F Dixon, A T R Axon
}

\begin{abstract}
A prospective surveillance programme for patients with longstanding $(>=8$ years), extensive ( $>=$ splenic flexure) ulcerative colitis was undertaken between 1978 and 1990. It comprised annual colonoscopy with pancolonic biopsy. One hundred and sixty patients were entered into the programme and had 739 colonoscopies ( 4.6 colonoscopies per patient; 709 patient years follow up). Eighty eight per cent of examinations reached the right colon. There was no procedure related death. One Dukes's A cancer was detected. Forty one patients $(25 \%)$ defaulted. Of these 25 remain well; 13 are unaccounted for, and one died from colonic cancer. One patient had colectomy for medical reasons, and another died of carcinoma of the pancreas. Retrospectively an additional 16 eligible patients were identified who had not been recruited. Of these, 14 remain well, two are unaccounted for. None developed colonic cancer. Four patients refused colonoscopy. All remain well. Over the same period seven other cases of colonic cancer were found in association with ulcerative colitis, two in patients who had erroneously been diagnosed as having only proctitis and were therefore not entered into the programme, but were found at operation to have total colitis, one in a patient with colitis of seven years duration, and four patients who had previously attended the clinic but had been lost to follow up before 1978 and then had represented with new symptoms during the surveillance period. Thus, of the nine colitis related cancers diagnosed in this centre during the study period only one was detected by the surveillance programme. The results of this large study, and a review of published works, cast doubts on the effectiveness of colonoscopic surveillance programmes in detecting colorectal cancer in patients with ulcerative colitis.
\end{abstract}

(Gut 1993; 34: 1075-1080)

Colorectal carcinoma was recognised as a complication of ulcerative colitis over 65 years ago. ${ }^{1}$ The risk of developing cancer is increased in those individuals who have had extensive colitis for more than 10 years after the first attack, the cumulative cancer rate being $7 \%$ at 20 years and $17 \%$ at 30 years disease duration. ${ }^{2}$ Such was the perceived risk of a patient developing cancer that prophylactic colectomy has been recommended. ${ }^{3-6}$

The strong association between colorectal dysplasia and cancer in ulcerative colitis was described in 1967. ${ }^{7}$ The development of flexible endoscopy, which allows pancolonic biopsy, has supported this finding ${ }^{8-15}$ and has led to a change in practice such that in many centres at risk patients are examined at intervals, with colonoscopy and biopsy, to detect premalignant dysplasia or early cancer.

These cancer surveillance programmes are now widely implemented despite not having been subjected to clinical trial. A number of reports ${ }^{8-17}$ have supported the use of colonoscopic surveillance in ulcerative colitis, but doubts have also been expressed about its efficacy. ${ }^{18} 19$

Surveillance programmes are expensive, time consuming, and unpleasant for patients and should be shown to be effective before implementation. Colonoscopic surveillance in colitis should reduce cancer related death compared with routine clinical care, by detecting early curable cancer. It might be deemed unethical, however, to perform a controlled trial. Gastroenterologists, therefore, have a responsibility to review their results to show whether or not this form of surveillance is effective.

In 1978 a prospective surveillance programme was started ${ }^{914}$ whereby all patients with longstanding extensive ulcerative colitis were invited to have annual colonoscopy with biopsy. In this paper the results of this large programme and other reported series are reviewed to discover if colonoscopic surveillance works.

\section{Methods}

SURVEILLANCE PROGRAMME

From 1978 to December 311990 all patients with longstanding $(>=8$ years) and extensive (disease extending to or beyond the splenic flexure) ulcerative colitis were advised to have annual colonoscopy with pancolonic biopsy.

Patients were seen at routine clinic follow up and the reasons for surveillance explained. If the patient failed to attend for their clinic/colonoscopy then a repeat appointment was made. If a second reminder was unsuccessful no further action was taken. If patients were known to be moving away a letter detailing their surveillance history was sent to their doctor or next supervising consultant.

The duration of disease was taken from the date of diagnosis except where obvious symptoms of colitis came before the diagnosis by a matter of years. Disease extent was verified by barium enema or colonoscopy, or both. Patients older than 75 years were not entered and those reaching 75 during surveillance were withdrawn.

Colonoscopy was carried out under light sedation after standard laxative and bowel enema preparation. Biopsy specimens were taken with forceps from flat mucosa at about $10 \mathrm{~cm}$ intervals 
along the colorectum and from any identifiable 'mass lesions'. These correspond to the following descriptive sites: caecum; proximal ascending colon; distal ascending colon; proximal transverse colon; distal transverse colon; proximal descending colon; distal descending colon; sigmoid colon; rectum. Biopsy specimens were mounted on filter paper or placed in cassettes before fixation in formalin and after routine processing were sectioned at three levels and stained with haematoxylin and eosin.

If dysplasia was present it was classified as low grade, high grade, or carcinoma. If high grade dysplasia was found, repeat biopsies were performed within six months. Surgery was performed in cases of persistent high grade dysplasia, or carcinoma.

\section{DETERMINING OUTCOME OF SURVEILLANCE PROGRAMME}

Our review of the surveillance programme had three distinct goals: (a) to obtain full follow up of all patients who had participated at any time in the surveillance programme; (b) to identify any other patients who attended the department over this time and who should have been recruited into the surveillance programme; and (c) to identify all cases of colonic carcinoma occurring in association with ulcerative colitis presenting to the department over this period.

These goals were achieved as follows: (a) the outcome of patients entered into the surveillance programme was obtained from departmental records, patient case notes, histopathology reports, doctor, supervising consultant or patient by clinic, letter or telephone; (b) eligible patients with ulcerative colitis were identified from index cards used to document all colitis clinic patients, and review of notes of all patients attending the clinic for a 12 month period. Using this information notes were obtained from the records departments. Information extracted included date of birth, relevant medical and surgical history, date of onset of symptoms, date of diagnosis (histological/radiological), disease extent (barium enema/colonoscopy), surveillance colonoscopy date and findings, biopsy site and histological findings, and present status if known; (c) cases of cancer in association with

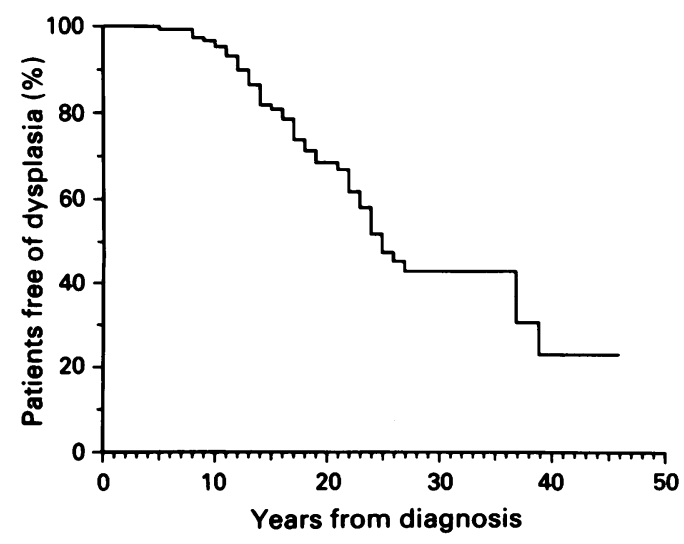

A low grade dysplasia free survival curve shows that $25 \%$ of patients with ulcerative colitis had exhibited low grade dysplasia at least once by 17 years after diagnosis of ulcerative colitis, $50 \%$ at 25 years, and $75 \%$ by 38 years. colitis were identified from histopathology department records that document all colitis patients who developed dysplasia, cancer, or had colonic surgery since 1978 .

\section{Results}

One hundred and eighty patients fulfilled the criteria for entry into the surveillance programme.

\section{RECRUITMENT FAILURES}

Sixteen patients were erroneously not entered into the programme by the supervising physician because they were unaware that the patient was eligible for surveillance. Fourteen of these patients are well, a mean of 9.4 years (range 3-12) after what should have been their programme entry date. Two are unaccounted for after a mean of three years.

\section{SURVEILLANCE REFUSALS}

Four patients refused colonoscopic surveillance, but continue with regular clinical supervision. All are well, a mean of 9.75 years (range 6-12) after programme entry date.

\section{PATIENTS STARTING SURVEILLANCE}

One hundred and sixty patients entered the surveillance programme and had 739 colonoscopies (4.6 colonoscopy/patient; 709 years follow up). The mean length of duration of colitis was $14 \cdot 1$ years (range $8-46$ ). Eighty eight per cent of examinations reached the right colon. There was no procedure related death. Biopsy specimens (5695) were taken giving a mean of $7 \cdot 8$ per colonoscopy (range $1-9$ ).

\section{SURVEILLANCE DEFAULTERS}

Forty one patients who started surveillance defaulted. Twenty five remain well, a mean of 2.5 years (range 2-10) after default. Thirteen patients are unaccounted for, mean 6.5 years (range 2-12) later. One patient died of disseminated colonic cancer after three years (see Table I, patient $E$ ), the three previous complete annual colonoscopies had been negative for dysplasia. One patient had colectomy for medical reasons six years later. No cancer was found. One patient died of pancreatic cancer seven years later.

LOW GRADE DYSPLASIA

Forty patients were found to have low grade dysplasia in at least one biopsy. The mean age at first diagnosis of low grade dysplasia was $45 \cdot 2$ years (SD 13.64) and mean duration of colitis to diagnosis of low grade dysplasia $17 \cdot 7$ years (SD 7.33).

These 40 patients had a further 201 colonoscopies (223 patient years follow up). Twenty $(50 \%)$ had no further dysplasia (mean 4.0 colonoscopies per patient over $4 \cdot 7$ years). Nineteen continued to exhibit low grade dysplasia in at least one subsequent biopsy (mean $6 \cdot 3$ follow up colonoscopies per patient over 6.9 years). One of 
TABLE I Colorectal cancer in ulcerative colitis 1978-1990

\begin{tabular}{|c|c|c|c|c|c|c|c|}
\hline $\begin{array}{l}\text { Year of } \\
\text { cancer } \\
\text { diagnosis }\end{array}$ & Age & Sex & $\begin{array}{l}\text { Duration } \\
\text { of } \\
\text { ulcerative } \\
\text { colitis } \\
\text { (years) }\end{array}$ & $\begin{array}{l}\text { Extent of colitis/ } \\
\text { method of } \\
\text { determination }\end{array}$ & Presentation & $\begin{array}{l}\text { Dukes's } \\
\text { stage }\end{array}$ & Patient group \\
\hline $\begin{array}{l}\text { Patient A } \\
1979\end{array}$ & 60 & $\mathbf{M}$ & 7 & $\begin{array}{l}\text { Total/ } \\
\text { colonoscopy }\end{array}$ & $\begin{array}{l}\text { Previous history of colonic polyps. } \\
\text { Colonoscopy performed at } 7 \text { years } \\
\text { duration to determine extent plus } \\
\text { polypectomy (Barium enema showed } \\
\text { recurrence of polyps) }\end{array}$ & A & $\begin{array}{l}\text { Did not fulfil eligibility } \\
\text { criteria }\end{array}$ \\
\hline $\begin{array}{l}\text { Patient B } \\
1983\end{array}$ & 49 & $\mathbf{F}$ & 20 & $\begin{array}{l}\text { Rectum/ } \\
\text { sigmoidoscopy }\end{array}$ & $\begin{array}{l}\text { Patient believed to have proctitis. } \\
\text { Diagnosed 1963. Lost to follow up. } \\
\text { Presented with symptoms 1983. Found to } \\
\text { have rectal carcinoma }\end{array}$ & B & $\begin{array}{l}\text { Did not fulfil eligibility } \\
\text { criteria }\end{array}$ \\
\hline $\begin{array}{l}\text { Patient } C \\
1984\end{array}$ & 45 & M & 21 & $\begin{array}{l}\text { Total/ } \\
\text { colonoscopy }\end{array}$ & $\begin{array}{l}\text { Patient entered surveillance } 1979 \text { at } 17 \text { years } \\
\text { duration. High grade dysplasia at fifth } \\
\text { colonoscopy. Colectomy performed }\end{array}$ & A & Surveillance \\
\hline $\begin{array}{l}\text { Patient D } \\
1984\end{array}$ & 33 & M & 12 & Total/barium & $\begin{array}{l}\text { Lost to follow up } 1972 \text {. Re-presented } 1984 \\
\text { with colitic symptoms. Barium enema } \\
\text { showed sigmoid polyp. Colonoscopy } \\
\text { showed high grade dysplasia. Colectomy } \\
\text { performed }\end{array}$ & A & $\begin{array}{l}\text { Lost to follow up before } \\
\text { programme }\end{array}$ \\
\hline $\begin{array}{l}\text { Patient E } \\
1985\end{array}$ & 36 & $\mathbf{M}$ & 18 & $\begin{array}{l}\text { Total } / \text { barium } \\
\text { enema }\end{array}$ & $\begin{array}{l}\text { Normal surveillance } 1980-82 \text {. Moved away } \\
1982 / 83 \text {. Died with a disseminated colon } \\
\text { carcinoma } 1985\end{array}$ & $>=C$ & Defaulter \\
\hline $\begin{array}{l}\text { Patient } F \\
1987\end{array}$ & 42 & $\mathbf{F}$ & 19 & $\begin{array}{l}\text { Total/ } \\
\text { colonoscopy }\end{array}$ & $\begin{array}{l}\text { Diagnosed 1968. Lost to follow up. } \\
\text { Presented with rectal bleeding } 1987 . \\
\text { Sigmoidoscopy showed polypoid, rectal } \\
\text { carcinoma. Anterior resection performed. } \\
\text { Patient entered into surveillance }\end{array}$ & C & $\begin{array}{l}\text { Lost to follow up before } \\
\text { programme }\end{array}$ \\
\hline $\begin{array}{l}\text { Patient } G \\
1988\end{array}$ & 47 & $\mathbf{M}$ & 20 & Unknown & $\begin{array}{l}\text { Lost to follow up in } 1970 \text {. Re-presented in } \\
1987 \text { with rectal bleeding. Colonoscopy } \\
\text { showed carcinoma in situ at } 80 \mathrm{~cm}\end{array}$ & C & $\begin{array}{l}\text { Lost to follow up before } \\
\text { programme }\end{array}$ \\
\hline $\begin{array}{l}\text { Patient } H \\
1990\end{array}$ & 62 & $M$ & 21 & Unknown & $\begin{array}{l}\text { Believed to have proctitis. Diagnosed } 1969 . \\
\text { Lost to follow up } 1972 \text {. Presented with } \\
\text { changed bowel habit } 1990 \text {. Ascending } \\
\text { colon and sigmoid cancer on barium } \\
\text { enema }\end{array}$ & C & $\begin{array}{l}\text { Did not fulfil eligibility } \\
\text { criteria }\end{array}$ \\
\hline $\begin{array}{l}\text { Patient I } \\
1990\end{array}$ & 44 & $\mathbf{M}$ & 26 & Unknown & $\begin{array}{l}\text { Diagnosed colitis 1964. Lost to follow up in } \\
\text { 1976. Presented with dysphagia and } \\
\text { anaemia in } 1990 \text {. Colonoscopy at that time } \\
\text { showed sigmoid polyp (cancer) }\end{array}$ & $\mathrm{C}$ & $\begin{array}{l}\text { Lost to follow up before } \\
\text { programme }\end{array}$ \\
\hline
\end{tabular}

This table shows the year of diagnosis, age at diagnosis, sex, duration of disease, disease extent (method used), presentation, Dukes's staging, and patient group for each of the nine cancers found in association with ulcerative colitis between 1978 and 1990.

these developed an adenoma six years later, which was removed at colonoscopy and has remained free of dysplasia since (6 years). One patient (patient $\mathrm{C}$ ) who had low grade dysplasia in the distal descending and sigmoid colon was found to have high grade dysplasia in the sigmoid colon at the next colonoscopy 14 months later. At colectomy two Dukes's A cancers were found; one in the sigmoid and one in the transverse colon. This patient was the only case of cancer detected by the surveillance programme.

Thus, follow up of patients with low grade dysplasia found one cancer in 223 patient years. The Figure shows that $25 \%$ of patients with ulcerative colitis exhibited low grade dysplasia on at least one occasion by 17 years after diagnosis of ulcerative colitis, $50 \%$ by 25 years, and $75 \%$ by 38 years.

\section{NON-CANCER SURGERY}

Fifteen patients had colectomy for failed medical treatment after a mean of 15.6 years (range 9-32) disease duration. Nine had subtotal colectomy, six had panproctocolectomy. Four of the patients who had low grade dysplasia previously were negative for dysplasia at colectomy. Two patients who had been negative for dysplasia were found to have low grade dysplasia in their colectomy specimens.

\section{CANCER COMPLICATING ULCERATIVE COLITIS} OUTSIDE THE SURVEILLANCE PROGRAMME

During the 12 year period there have been seven other cases of colonic cancer in association with ulcerative colitis at this centre. Two patients (patient $B$ and patient $\mathrm{H}$ ) were believed to have had proctitis but were subsequently found to have total colitis at colonoscopy with biopsy or histological examination of the colectomy specimen (one Dukes's B, one Dukes's C) (Table I). One patient (patient A) had several colonic polyps removed endoscopically two years earlier. A barium enema performed at seven years disease duration showed recurrent polyps. Colonoscopy was performed to remove the colonic polyps and determine disease extent. Total colectomy was performed because of incomplete removal of a large tubular adenoma with intra-epithelial malignant change. At colectomy a Dukes's A cancer was found on a background of total colitis. There were no other areas of dysplasia (Table I). Four patients (D, F, $G$, and I) had been seen in the Leeds colitis clinic before the policy of surveillance had been started 
TABLE II Breakdown of 12 (11 published) studies on cancer surveillance in ulcerative colitis

\begin{tabular}{|c|c|c|c|c|c|c|}
\hline Year & Author & $\begin{array}{l}\text { No of } \\
\text { patients }\end{array}$ & $\begin{array}{l}\text { Colonoscopies } \\
\text { per patient }\end{array}$ & $\begin{array}{l}\text { Dukes's } \\
>=C^{\star}\end{array}$ & $\begin{array}{l}\text { Dukes's } \\
\text { A/B } \\
\text { excludet }\end{array}$ & $\begin{array}{l}\text { Dukes's } \\
A / B \\
\text { successf }\end{array}$ \\
\hline $\begin{array}{l}1980 \\
1981 \\
1985 \\
1988 \\
1988 \\
1989 \\
1990 \\
1990 \\
1991 \\
1991 \\
1992 \\
\text { Sub total } \\
1993 \\
\text { Total }\end{array}$ & $\begin{array}{l}\text { Fuson }^{10} \\
\text { Blackstone }^{22} \\
\text { Rosenstock }^{12} \\
\text { Jones }^{20} \\
\text { Rutegard }^{15} \\
\text { Lashner }^{21} \\
\text { Lennard-Jones }^{22} \\
\text { Lofberg }^{24} \\
\text { Nugent }^{8} \\
\text { Leidenius }^{16} \\
\text { Woolrich }^{17} \\
\text { al } \\
\text { Lynch }\end{array}$ & $\begin{array}{r}75 \\
112 \\
248 \\
313 \\
93 \\
99 \\
344 \\
72 \\
713 \\
213 \\
66 \\
121 \\
1756 \\
160 \\
1916\end{array}$ & $\begin{array}{l}1.1 \\
1.5 \\
1.5 \\
? \\
3.6 \\
4.2 \\
2.4 \\
4.0 \\
? \cdot 0 \\
2.8 \\
3.7 \\
4.3\end{array}$ & $\begin{array}{r}4 \\
2 \\
3 \\
5 \\
0 \\
5 \\
8 \\
0 \\
6 \\
0 \\
2 \\
35 \\
5 \\
40\end{array}$ & $\begin{array}{r}7 \\
4 \\
4 \\
2 \\
1 \\
0 \\
13 \\
1 \\
3 \\
0 \\
3 \\
38 \\
3 \\
41\end{array}$ & $\begin{array}{r}0 \\
0 \\
0 \\
2 \\
0 \\
3 \\
1 \\
1 \\
1 \\
0 \\
2 \\
10 \\
1 \\
11\end{array}$ \\
\hline
\end{tabular}

^Patients found to have cancer, but stage Dukes's C or worse. †Patients found to have Dukes's A/B cancer, but not as part of the colonoscopic surveillance policy detailed in the discussion. $\ddagger$ Patients found to have cancer as part of surveillance programme.

and were lost to follow up. They re-presented during the surveillance period with new symptoms.

\section{CANCER SURGERY}

Thus, altogether, there were nine cases of colonic cancer in association with ulcerative colitis at this centre over this time period (Table I); mean age 46.4 years (range 33-62), mean disease duration 18.2 years (range $7-26$ ), six men. Six patients developed cancer under the age of fifty. Seven patients had total colectomy (three Dukes's A, one Dukes's B, three Dukes's C). One patient (patient F) who had been lost to follow up, had an anterior resection for a rectal carcinoma (one Dukes's C). Because of the high risk of developing a further cancer the patient was entered into the surveillance programme. Three subsequent colonoscopies have been negative for dysplasia.

Therefore, of 180 patients eligible for colonic cancer surveillance in ulcerative colitis 160 were entered into the programme. During the 12 year period 1978-1990 nine colonic cancers were found in association with ulcerative colitis, but only one was detected by the surveillance programme.

\section{Discussion}

Many gastroenterologists consider that patients with ulcerative colitis with longstanding, extensive disease should have annual colonoscopy and biopsy to detect dysplasia or early cancer. If high grade dysplasia or carcinoma is detected the patient can be treated at an early stage.

It is important to define what is 'success' and what is 'failure' in a surveillance programme to allow critical analysis of the outcome. An early cancer - that is, Dukes's A or B found as a result of the programme represents a success. A Dukes's C cancer or worse should be regarded a failure of surveillance because of the uncertain outlook.

It is also important to consider the method of cancer detection when reviewing the results of a surveillance policy. The generally accepted surveillance policy in most centres today is regular colonoscopy for patients with longstanding extensive colitis. If this definition is applied when reviewing surveillance studies the result is that cancers found earlier than eight years from onset or found in left sided colitis or a cancer found at colonoscopy performed for any reason other than surveillance (such as rectal bleeding), cannot be regarded as a success. Colorectal cancer presenting as an abdominal mass or perforation, ${ }^{2021}$ cancers found on sigmoidoscopy and barium enema, ${ }^{20}$ or colonoscopy performed because of an abnormal barium enema $^{102223}$ are outside protocols that use regular colonoscopic examination as the surveillance technique.

Similarly, if a cancer is found at a screening colonoscopy in a patient presenting to a unit years after the programme entry date for example, colitis of 17 years duration or when referred from another centre ${ }^{810224}$ it cannot be counted a success becaue these cancers represent a selected group detected outside the regular surveillance protocol. Cancers found at surgery performed for reasons other than high grade dysplasia or early carcinoma, such as debility or failed medical treatment, ${ }^{122}$ or low grade dysplasia, ${ }^{8123}$ (not a generally recognised indication for surgery) cannot be counted as successes of the surveillance policy either.

Applying these criteria to our results, one of nine colonic cancers that arose in association with ulcerative colitis during the surveillance period was detected by the surveillance programme. Analysis of 12 published studies of colonoscopic surveillance programmes (Tables II and III) shows that 93 cases of colonic cancer were found. Twelve (13\%) of these represent successes for the colonoscopic surveillance programmes - that is, Dukes's A/B cancers detected by regular colonoscopic surveillance.

It could be argued that these criteria are too rigid. Some surveillance programmes entail routine clinical follow up, regular sigmoidoscopy, and barium enema examination as well as regular colonoscopy and biopsy. ${ }^{22}$ These methods of cancer detection are equally valid if they are laid down as part of a surveillance protocol. Also, cancers found at the screening (first) colonoscopy may be regarded as a success

TABLE III Ulcerative colitis surveillance papers (amalgamated results of 1916 patients). Method of cancer diagnosis

\begin{tabular}{|c|c|c|c|c|c|c|c|c|}
\hline $\begin{array}{l}\text { Dukes's } \\
\text { stage }\end{array}$ & $\begin{array}{l}\text { Mass/ } \\
\text { perforation. } \\
\text { Other signs/ } \\
\text { symptoms }\end{array}$ & $\begin{array}{l}\text { Barium enemal } \\
\text { sigmoidoscopy }\end{array}$ & $\begin{array}{l}\text { Barium } \\
\text { enema leading } \\
\text { to colonoscopy }\end{array}$ & $\begin{array}{l}\text { Operation or } \\
\text { necropsy }\end{array}$ & $\begin{array}{l}\text { Operation for } \\
\text { low grade } \\
\text { dysplasia }\end{array}$ & $\begin{array}{l}\text { Colonoscopy } \\
\text { without entry } \\
\text { criteria } \\
\text { fulfilled }\end{array}$ & $\begin{array}{l}\text { Screen } \\
\text { colonoscopy }\end{array}$ & $\begin{array}{l}\text { Surveillance } \\
\text { colonoscopy }\end{array}$ \\
\hline$>=\begin{array}{r}\text { C } \\
\text { B } \\
\text { A }\end{array}$ & 13 & $\begin{array}{r}10 \\
6 \\
4\end{array}$ & $\begin{array}{l}5 \\
5 \\
2\end{array}$ & $\begin{array}{l}1 \\
5 \\
6\end{array}$ & $\begin{array}{l}1 \\
2\end{array}$ & 3 & $\begin{array}{l}2 \\
1 \\
7\end{array}$ & $\begin{array}{l}8 \\
5 \\
6\end{array}$ \\
\hline
\end{tabular}

Of the 1916 patients from the 12 studies, 92 cancers were found.

This table indicates the Dukes's staging and the method of diagnosis of the colonic cancers. 
when the examination is performed according to the protocol. Adopting this approach the number of successes in the 12 published studies is $24(26 \%)$.

A workable surveillance programme requires defined entry criteria and a cheap simple test, which is acceptable to the patient and which has a sound discriminatory basis. ${ }^{25}$ Current surveillance colonoscopy programmes in ulcerative colitis fall short in a number of ways.

There are no universally accepted entry criteria for cancer surveillance. ${ }^{26-28}$ There is a general feeling in published studies that colitis extending beyond the splenic flexure can be regarded as extensive in terms of cancer risk. Assessment of extent, however, may be by barium enema, colonoscopy or both. Barium studies seem to be insensitive to microscopic involvement ${ }^{29}$ and may detect only more severe cases. In our study two patients were originally diagnosed as having proctitis. If colonoscopy had been done the extensive nature of the disease might have been recognised and the patient would have entered the programme. Colitis for at least eight years is considered to be longstanding. In this series, however, one patient developed cancer after seven years disease duration so perhaps the criteria for entry should be widened.

Colonscopic surveillance programmes cause a heavy clinical workload as well as a substantial capital outlay ${ }^{19}$ - that is, the test is not simple or cheap.

Patient recruitment is a recognised problem; $12 \%$ were not recruited into our programme. Some were lost to follow up from clinic before fulfilling the entry criteria for longstanding disease; others despite being eligible, were not entered. Once recruited, patients had a regular, uncomfortable examination that requires a day off work. In our study four patients refused colonoscopy, and $41(27 \%)$ patients defaulted from the programme - strong evidence that annual colonoscopy is unacceptable to many.

There are problems with the discriminatory power of colonoscopy and biopsy. Colonic epithelial dysplasia is patchy. ${ }^{30} 31$ Multiple biopsies sample much less than $1 \%$ of the surface area of the colon. The evidence for the association of dysplasia and cancer is conflicting. Twenty to fifty per cent of cancers are thought to arise de novo. ${ }^{32}$ Fozard et al found a weak association between colon cancer and distant dysplasia. ${ }^{33}$ By contrast two other studies conclude that the association is invariable. ${ }^{12}{ }^{34}$ The histological interpretation of biopsy specimens and diagnosis of dysplasia is fraught with the problems of inter and intraobserver variation ${ }^{35} 36$ - that is, the diagnostic test does not have a sound discriminatory basis. The histological recognition of dysplasia is the very cornerstone of surveillance yet it would seem that the process of tissue collection to final diagnosis is susceptible to a number of pitfalls.

It can be argued that the finding of high grade dysplasia without cancer should be considered to be a success of surveillance. This argument is not straightforward. The diagnosis of dysplasia is beset with problems, as discussed above, furthermore the significance and outcome of high grade dysplasia is unpredictable. Colon cancer was found in $25 \%$ of patients with high grade dysplasia but another $25 \%$ had a negative colectomy specimen or colonoscopy on follow up..$^{22}$ In another study while $33 \%$ of patients with high grade dysplasia developed cancer within six years $33 \%$ were not operated on and were alive and well five years later so not all authors have advised operation even when high grade dysplasia has been diagnosed. ${ }^{12} 15$ Low grade dysplasia was a common finding in ulcerative colitis surveillance in our study and in others ${ }^{21}$ and has little prognostic significance.

All but one of the colorectal cancers in this series occurred in patients outside the surveillance programme. This experience is not unique. ${ }^{2022}$ This cannot be construed as a criticism of the surveillance protocol itself. Only one of these patients had been recruited and had then defaulted. We are not aware of any extensive cancer arising in patients who had regular surveillance colonoscopy. It is apparent, however, that a number of patients who needed surveillance did not receive it. It is probable that these individuals were well and asymptomatic or had minimal symptoms. This might explain why they did not attend for clinical review. A review of the notes of our cancer patients suggests that virtually none of them were taking disease suppressant drugs, such as salazopyrin, regularly or at all. It may be that unsuppressed inflammation, while causing few or no symptoms, places these patients at increased risk of developing colonic cancer.

The main criticism that can be levelled at our study (and those in published works) is that the finding of one patient with high grade dysplasia (and carcinoma) does not justify the great expense and the effort for staff and patients involved in 739 colonscopies and 709 years of follow up. In 10 of 12 surveillance studies it is possible to calculate the number of colonoscopies performed and the number of early cancers detected by them. Including this study eight early cancers were found by colonoscopic surveillance and 3807 colonoscopies were performed: one cancer per 476 examinations.

There are 38 deaths per $100000^{37}$ from colorectal cancer annually in the United Kingdom. As nearly all of these occur in the 40-80 age group (and not everyone with colorectal cancer dies of it) the annual incidence in this group is greater than 38 per $50000 .{ }^{37}$ If, therefore, the normal population in this age group was screened at five year intervals, and assuming that the polyp/carcinoma sequence takes longer than five years, 190 cases of cancer or premalignant polyp would be found per 50000 examinations - that is, 1 in 263: a higher detection rate in the normal population than that achieved by annual colonoscopic surveillance of extensive longstanding ulcerative colitis. In a recent study colonoscopy was performed on 210 asymptomatic subjects aged $50-75$ years with negative faecal occult bloods. Two Dukes's A cancers were detected giving a yield of one cancer per 105 colonoscopies. ${ }^{38}$

We conclude that in our experience annual colonoscopic surveillance for cancer has been unsuccessful; eight of nine colonic cancers 
occurred in ulcerative colitis patients not having surveillance. Our results and a review of published works cast doubts on the value of annual colonoscopic surveillance in this condition when considering its cost effectiveness and the definition of a workable programme. ${ }^{24}$

Lashner et $a l^{39}$ monitored two groups of 90 patients with longstanding, extensive ulcerative colitis, one with regular colonoscopy, the other with regular clinical follow up. There was no difference in the cancer detection rate. Though the numbers affected are small colonoscopic biopsy and histological examination for dysplasia seems to hold no advantage over routine clinical management.

How then should we manage these patients who are known to be at an increased risk of developing cancer?

The published data show that most cancers are detected as a result of clinical follow up, where new symptoms are investigated at an early stage. Many cancers were found in patients who had defaulted the clinic before they were eligible for surveillance returning with new symptoms years later. 'Screening' colonoscopy (as opposed to 'surveillance' colonoscopy) detected a number of cancers.

All patients with ulcerative colitis should be screened at eight years. This will allow them to be assessed microscopically as 'total', 'extensive', or 'left sided' providing important information about their cancer risk. All patients with colitis should be followed up indefinitely. It is difficult to justify regular colonoscopy thereafter.

Clinicians faced with a patient with longstanding colitis, at increased risk of developing colonic cancer, feel compelled to do, or be seen to do, something. There is also an obligation, however, to use effective methods. The argument for colonoscopic surveillance is not convincing. While it has been deemed unethical to perform a controlled clinical trial, it could be argued that the use of limited resources on surveillance programmes of unproved value is also unethical. The funds released by ending surveillance are considerable. They could be channelled into a more cost effective cancer prevention scheme. It is time to review cancer surveillance in ulcerative colitis.

We would like to thank Mrs Olive Bell, Miss Julie Mackintosh and Mrs Andrea Scales for their help in the preparation and typing of this paper.

These data were published in abstract form in Gut 1991; 32 . A556 and A561.

1 Crohn BB, Rosenberg H. The sigmoidoscopy picture of chronic ulcerative colitis (non-specific). Am $\mathcal{f} M e d S_{c i} 1925$ 170: $220-8$

2 Gyde SN, Prior P, Allan RN, Stevens A, Jewell DP, Truelove SC, et al. Colorectal cancer in ulcerative colitis: a cohort study of primary referrals from three centres. Gut 1988; 29: 206-17.

3 de Dombal FT, Watts JMcK, Watkinson G, Goligher JC Local complications of ulcerative colitis: stricture, pseudopolyposis, and carcinoma of the colon and rectum. $B M \mathcal{F}$ polyposis, and carc

4 Devroede GJ, Taylor WF, Sauer WG, Jackman RJ, Stickle GB. Cancer risk and life expectancy of children with GB. Cancer risk and life expectancy of child
ulcerative colitis. $N$ Engl $\mathcal{M}$ Med 1971; 285: 17-21.

5 Kewenter J, Ahlman $\mathrm{H}$, Hulten $\mathrm{L}$. Cancer risk in extensive colitis. Ann Surg 1987; 188: 824-7.

6 MacDougal IPM. The cancer risk in ulcerative colitis. Lance 1964; ii: $655-8$.
7 Morson BC, Pang LSC. Rectal biopsy as an aid to cancer control in ulcerative colitis. Gut 1967; 8: 423-34.

8 Nugent FW, Haggit RC, Gilpin PA. Cancer surveillance in ulcerative colitis. Gastroenterology 1991; 100: 1241-8.

9 Dickinson RJ, Dixon MF, Axon ATR. Colonoscopy and the detection of dysplasia in patients with longstanding ulcerative colitis. Lancet 1980; ii: $620-2$.

10 Fuson JA, Farmer RG, Hawk WA, Sullivan BH. Endoscopic surveillance for cancer in chronic ulcerative colitis. $A m \mathcal{F}$ Gastroenterol 1980; 73: 120-6.

11 Lennard Jones JE, Morson BC, Ritchie JK, Williams C. Cancer surveillance in ulcerative colitis: experience over 15 years. Lancet 1983; ii: 149-52.

12 Rosenstock E, Farmer RG, Petras R, Sivak MV, Rankin GB, Sullivan BH. Surveillance for colonic carcinoma in un GB, tive colitis. Gastroenterology 1985; 89: 1342-6.

13 Brostrom O, Lofberg R, Ost A, Reichard H. Cancer surveil lance of patients with longstanding ulcerative colitis: clinical, endoscopical, and histological study. Gut 1986; 27 1408-13.

14 Manning AP, Bulgim OR, Dixon MF, Axon ATR. Screening by colonoscopy for colonic epthelial dysplasia in inflammatory bowel disease. Gut 1987; 28: 1489-94.

15 Rutegard J, Ahsgren L, Stenling R, Janunger KG. Ulcerative colitis. Cancer surveillance in an unselected population. Scand 7 Gastroenterol 1988; 23: 139-45.

16 Leidenius M, Killokumpu I, Husa A, Riitula M, Sipponen P Dysplasia and carcinoma in longstanding ulcerative colitis: an endoscopic and histological surveillance programme. $G u t$ 1991; 32: 1521-5.

17 Woolrich AJ, DaSilva MD, Korelitz BI. Surveillance in the routine management of ulcerative colitis: the predictive value of low-grade dysplasia. Gastroenterlogy 1992; 103 : 431-8.

18 Gyde S. Screening for colorectal cancer in ulcerative colitis: dubious benefits and high costs. Gut 1990; 31: 1089-97.

19 Collins RH, Feldman M, Fordtran JS. Colon cancer, dysplasia, and surveillance in patients with ulcerative colitis. A critical review. N Englf Med 1987; 316: 1654-8.

20 Jones HW, Grogono J, Hoare AM. Surveillance in ulcerative colitis: burdens and benefit. Gut 1988; 29: 325-31.

21 Lashner BA, Silverstein MD, Hanaver SB. Hazard rates for dysplasia and cancer in ulcerative colitis. Dig Dis Sci 1989; 34: $1536-41$.

22 Lennard-Jones JE, Melville DM, Morson BC, Ritchie JK, Williams CB. Precancer and cancer in extensive ulcerative colitis: findings among 401 patients over 22 years. Gut 1990 31: $800-6$

23 Blackstone MO, Riddell RH, Rogers BHG, Levin B Dysplasia-associated lesion or mass (DALM) detected by colonoscopy in longstanding ulcerative colitis: an indication for colectomy. Gastroenterology 1981; 80: 366-74.

24 Lofberg R, Brostrom O, Karlen P, Tribukait B, Ost A Colonoscopic surveillance in longstanding total ulcerative colitis - a 15 year follow-up study. Gastroenterology 1990; 99 . 1021-31.

25 Weil J, Langman MJS. Screening for gastrointestinal cancer: an epidemiological review. Gut 1991; 32: 220-4.

26 Lennard Jones JE, Morson BC, Ritchie JK, Shove DC Williams CB. Cancer in colitis: assessment of the individual risk by clinical and histological criteria. Gastroenterolog risk by clinical and

27 Anonymous. Colorectal carcinoma in ulcerative colitis [Editorial]. Lancet 1986; ii: 197-8.

28 Morson BC. Precancer and cancer in inflammatory bowe disease. Pathology 1985; 17: 173-80.

29 Lennard-Jones JE. Compliance, cost, and common sense limi cancer control in colitis. Gut 1986; 27: 1403-7.

30 Ransohoff DF, Riddell RH, Levin B. Ulcerative colitis and colonic cancer: problems in assessing the diagnostic usefulness of mucosal dysplasia. Dis Colon Rectum 1985; 26 : 382-8.

31 Cook MG, Goligher JC. Carcinoma and epithelial dysplasia complicating ulcerative colitis. Gastroenterology 1975; 68 1127-36.

32 Riddell RH. The precarcinomatous phase of ulcerative colitis Curr Top Pathol 1976; 63: 179-219.

33 Fozzard JBJ, Griffiths SB, Dixon MF, Axon ATR, Giles GR Lectin and mucin histochemistry as an aid to cance surveillance in ulcerative colitis. Histopathology 1987; 11 385-94

34 Cuvelier CA, Morson BC, Roels HJ. The DNA content in cancer and dysplasia in chronic ulcerative colitis. Histopathology 1987; 11: 927-39.

35 Dixon MF, Brown CTR, Gilmore HM, et al. Observer variation in the assessment of dysplasia in ulcerative colitis. Histopathology 1988; 13: 385-97.

36 Melville DM, Jass JR, Shepherd NA, Northover JMA Capellano D, Richman PI, et al. Dysplasia and deoxyribonucleic acid anich changes in chronic ulcerative colitis. Observer

37 Fielding LP, - Blesovsky L. Clinical features of colorectal cancer. In: Misiewicz JJ, Pounder RE, Venables CW, eds Diseases of the gut and pancreas. Oxford: Blackwell Scientific

38 Rex DK, Lehman GH, Hawes RH, Ulbright TM, Smith JJ Screen colonoscopy in asymptomatic average - risk person with negative occult blood tests. Gastroenterology 1991; 100 64-7.

39 Lashner BA, Kane SV, Hanauer SB. Colon cancer surveillance in chronic ulcerative colitis: historical cohort study. Am $\mathcal{F}$ Gastroenterol 1990; 85: 1083-7. 